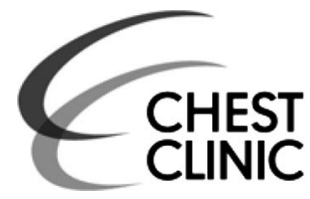

${ }^{1}$ Division of Thoracic Surgery, University Hospital Zurich,

Zurich, Switzerland

${ }^{2}$ Institute of Pathology,

Stadtspital Triemli, Zurich,

Switzerland

${ }^{3}$ Department of Pathology and Molecular Pathology, University Hospital Zurich, Zurich Switzerland

\section{Correspondence to} Professor W Jungraithmayr, Division of Thoracic Surgery, University Hospital Zurich, Raemistrasse 100, Zurich 8091, Switzerland; wolfgang. jungraithmayr@usz.ch

$\mathrm{KB}, \mathrm{SL}, \mathrm{BV}$, WJ contributed equally.

Received 17 May 2016 Revised 17 July 2016

Accepted 17 August 2016

Published Online First

8 September 2016

\title{
Placental transmogrification of the lung presenting as progressive symptomatic bullous emphysema
}

\author{
K Brüstle, ${ }^{1}$ S Lema, ${ }^{1}$ P Komminoth, ${ }^{2}$ W Weder, ${ }_{1}^{1}$ B Vrugt, ${ }^{3}$ W Jungraithmayr ${ }^{1}$
}

In 2015, a 63-year-old non-smoking male with a history of bullous emphysema, for which a wedge resection of the right lower lobe had been performed in 1972, presented with progressive dyspnoea on exertion and coughing. Pulmonary function tests demonstrated a moderate obstructive pattern with normal diffusion capacity $\left(\mathrm{FEV}_{1}\right.$ : 61\%, FVC: 64\%, TLco: $86 \%$ ). CT of the thorax revealed localised bullous-cystic changes in the right lower lobe with displacement of the mediastinum to the contralateral side (figure 1). Due to the patient's increasing respiratory distress, a right lower lobectomy was performed.

Grossly, the specimen displayed multiple cysts with compression of the adjacent parenchyma (figure 2A). Histologically, placenta-like papillary structures characterised by clear cell proliferation admixed with fat tissue were observed. The clear cells expressed vimentin and CD10 but were negative for HMB-45. This histological pattern was consistent with placental lung transmogrification (PLT) (figure 2B, C). Based on these findings, the histology of the resected specimen from 1972 was revised. This specimen revealed an interstitial proliferation of CD10-positive clear cells, whereas placental-like papillary formations and generalised emphysematous changes were lacking (figure 2D), suggesting that the currently diagnosed PLT evolved from a progressively growing bullous-like lesion from 1972 .

PLT is regarded as a rare variant of bullous emphysema that mainly affects young to middle-aged subjects. ${ }^{1}$ Clinical symptoms include dyspnoea, coughing, pneumonia, chest pain and
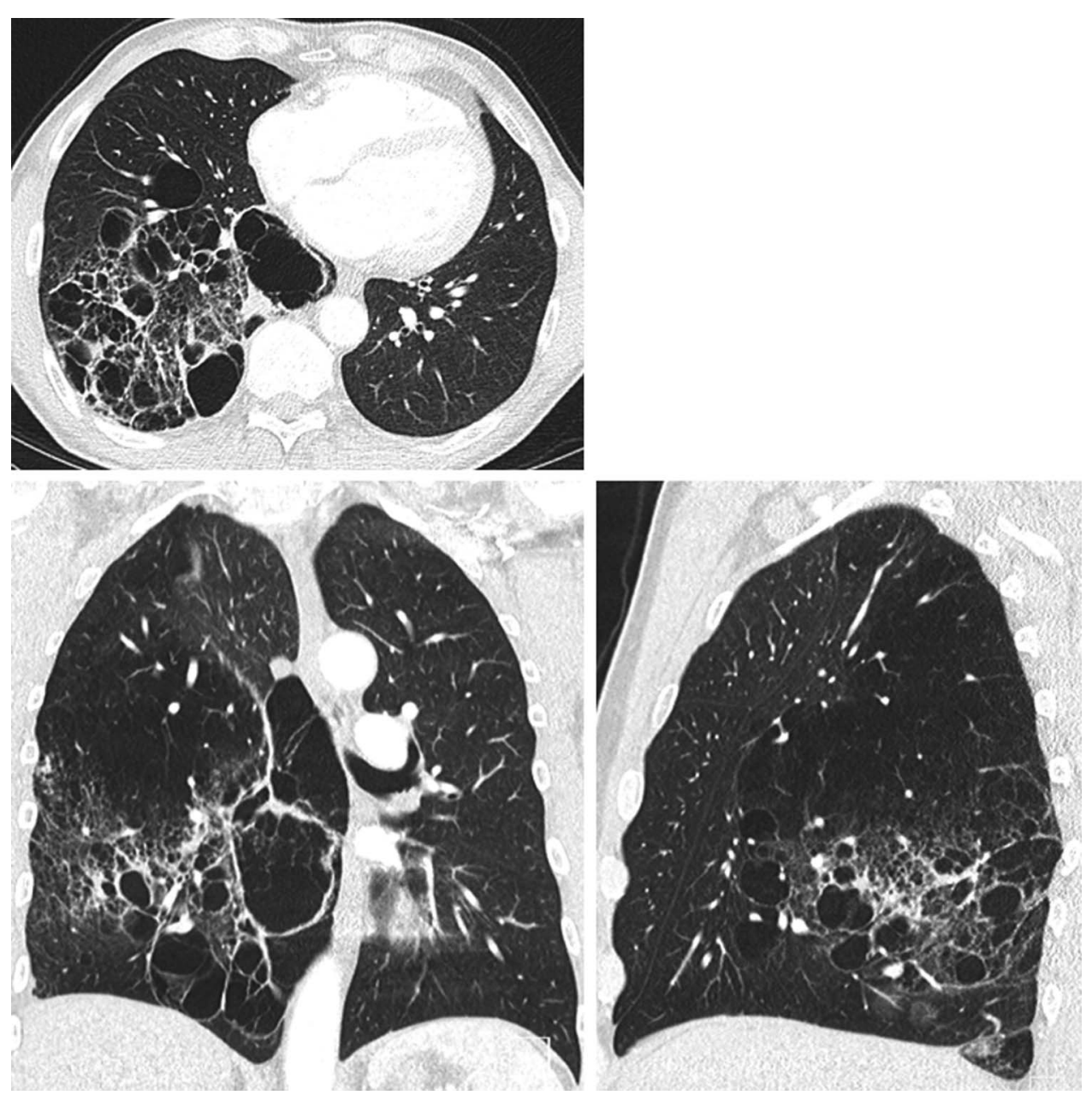

To cite: Brüstle $K$, Lema $S$, Komminoth $\mathrm{P}$, et al. Thorax 2017;72:284-285.

Figure 1 CT of the thorax showing bullous-cystic changes with atelectasis of the adjacent parenchyma and displacement of the upper lobe and mediastinum. 


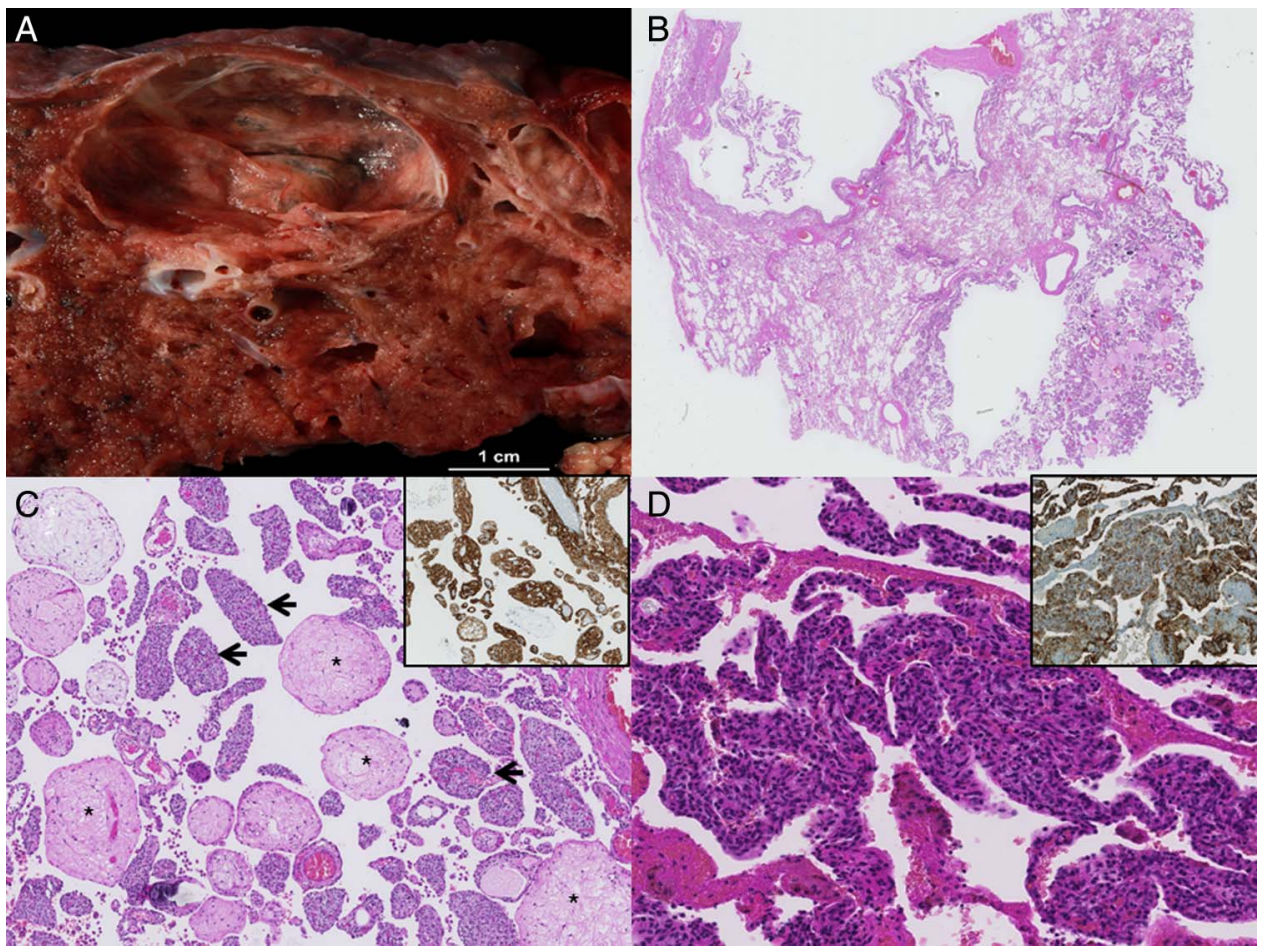

Figure 2 Macroscopic $(A)$ and histological appearance $(B$, magnification $\times 40)$ of placental lung transmogrification. Cystic changes cause a compression of the adjacent parenchyma grossly resembling placental tissue (A). Histology demonstrates placenta-like papillary structures (arrows) dominated by clear cells expressing CD10 (asterisks) $((C)$ and inset, magnification $\times 100)$. The CD10-positive clear cell component could also be recognised in the resected specimen from 1972 ((D) and inset, magnification $\times 100)$.

pneumothorax. $^{2}$ Due to the slowly progressive nature of the disease, PLT may lead to functional impairment and adverse events, including infections or, as in the present case, compression of the contralateral lung due to mediastinal displacement. Surgical treatment of PLT in the form of lobectomy is adequate and effectively eliminates the risk of recurrent infections and improves lung function.

From a clinicopathological point of view, the differential diagnosis of PLT includes congenital pulmonary airway malformation (CPAM), bullous emphysema, fibrochondromatous hamartoma and lymphangioleiomyomatosis. However, lymphangioleiomyomatosis is improbable in this case as this disease is almost exclusively found in female patients. In the present case, histology, especially the lack of an interstitial clear cell component, was inconsistent with CPAM and emphysema. The clear cell proliferation mimics perivascular epithelioid cell-related disorders, including lymphangioleiomyomatosis or clear cell 'sugar' tumours, whereas from the clinical-radiological presentation, the characteristic histology and CD10 expression in the absence of HMB-45 immunoreactivity favour PLT. Histologically, hamartoma may simulate PLT because it sometimes contains fat tissue and displays a pseudopapillary, placental villi-like growth pattern. However, hamartomas are well-circumscribed masses that lack interstitial clear cells. It remains to be established whether the lipomatous change observed in PLT is attributable to metaplastic mesenchymal differentiation of the clear cell component.
To the best of our knowledge, this is the first case of progressing PLT with clear cell proliferations found in two consecutive resections. Cavazza et $a l^{3}$ identified genotypical alterations in the clear cell component only, but not in the adjacent normal tissue. These data suggest that clear cells play a pivotal role in the pathogenesis and progression of PLT and support the concept that this rare disease cannot be interpreted as a variant of emphysema despite the striking clinical-radiological similarities.

Contributors KB wrote and drafted the manuscript (MS), SL drafted the MS, BV and PK contributed the histology and co-wrote the MS, WW co-wrote the MS, and WJ wrote and drafted the MS.

Competing interests None declared.

Patient consent Obtained.

Provenance and peer review Not commissioned; externally peer reviewed.

\section{REFERENCES}

1 Horsley WS, Gal AA, Mansour KA. Unilateral giant bullous emphysema with placental transmogrification of the lung. Ann Thorac Surg 1997;64:226-8.

2 Dunning K, Chen S, Aksade A, et al. Placental transmogrification of the lung presenting as tension pneumothorax: case report with review of literature. J Thorac Cardiovasc Surg 2008;136:778-80, 780.e1-8.

3 Cavazza A, Lantuejoul S, Sartori G, et al. Placental transmogrification of the lung: clinicopathologic, immunohistochemical and molecular study of two cases, with particular emphasis on the interstitial clear cells. Hum Pathol 2004;35:517-21. 